\title{
Assessment of outcomes associated with a Moodle-based lesson design for a research course in pharmacy education: An experimental pilot process validation study
}

\author{
Syed Wasif Gillani, Shabaz Mohiuddin Gulam, Jumana Al-Salloum, Rizah Anwar Assadi \\ College of Pharmacy, Gulf Medical University, Ajman, United Arab Emirates
}

\section{Keywords}

Course evaluation

Moodle online teaching

Pharmacy education

Research activity

Student self-reflection

\section{Correspondence}

Syed Wasif Gillani

Department of Pharmacy Practice

College of Pharmacy

Gulf Medical University

Ajman

United Arab Emirates

dr.syedwasif@gmu.ac.ae

\begin{abstract}
Background: This study aims to evaluate the effectiveness of an online Moodle-based lesson for pharmacy students developed and designed for a research course focused on different methodologies, study variables, and research process applications. Methods: An experimental research methodology was used to determine the effectiveness of the Moodle-based lesson. All fourth term Pharm.D. students were required to complete and provide self-reflection reports. The outcome variables were cluster-based completion time, earned score, subjective feedback on contents, gender differences, and performance. Mean values were used to conduct statistical analysis, and a logistic regression model was applied to identify the significance of independent variables. Results: A total of 35 students completed the Moodle-based lesson. The mean earned score for the module was $81.0 \%$, with an average completion time of 28.5 (range 26.8-30.1) hours. Females showed completion in less time compared to males. The reported knowledge and understanding showed a significant $(p<0.001)$ pre-post increase in mean percentages in all three clusters. The intragroup pool analysis also reported significant $(p<0.001)$ differences among gender and performance. The general feedback was limited to technical difficulties and selfreflection questions. Conclusions: The findings of this study showed that the online Moodlebased lesson module for a research course is an effective and validated tool to improve the knowledge and understanding of pharmacy students.
\end{abstract}

\section{Introduction}

On 30 January 2020, the World Health Organization (WHO) declared COVID-19 a public health emergency of international concern (PHEIC). All countries were advised to initiate strategies such as avoiding travel, preventing secondary transmission, promoting early detection, among other measures (International Health Regulation - WHO, 2020). Covid-19 had spread rapidly, leading to a 13-fold rise in cases, which then was characterised as a pandemic (Media briefing - WHO, 2020). Other worrisome effects were on the economy, employment, leisure and hospitality, travel sector, and education sector (Muro, Maxim \& Whiton, 2020). Precautionary measures have been taken globally to cope and reduce the spread of the virus. According to UNESCO (United
Nations Educational, Scientific and Cultural Organization), more than 190 countries have resorted to swift closure of schools and universities, thus affecting almost $90 \%$ of the student's world population (UNESCO, 2020 \& MOE UAE, 2020). However, the closure of schools and universities has not led to halting education. Indeed, with technological advancement, traditional teaching has been changed into modern online teaching. In the UAE, the government has announced the closure of schools and universities until the end of the academic year and has instructed them to continue classes through distance mode (Ko \& Rossen, 2017).

Shifting from traditional style, i.e., where the instructor and student are in a classroom, to online teaching should be carried out with proper planning. Online teaching or 
e-learning is defined as delivering a course with the help of the internet, e.g. using applications, Learning Management Systems, or others (Sun \& Chen, 2016). A review has reported these components as effective in online teaching: cognitive, teaching, and social presence, pedagogical practice, online course design, in addition to interactivity, collaboration, and online learning community (Wong, Greenhalgh \& Pawson, 2010). It was then suggested that both the teachers and students should jointly interact and collaborate to carry out effective online learning.

Furthermore, there is a need to measure the quality of education provided through distance learning. The literature has reported that Kirkpatrick's Hierarchy Model is widely used to assess the effectiveness of distance teaching, in addition to the traditional teaching type (Cook et al., 2008; Cook et al., 2010, Yardley, 2012). It is vital to understand the aspects of the e-learning context: first comes the reaction that measures satisfaction. It is followed by learning that measures attitude, knowledge, confidence, and skills, then the behaviour that evaluates the application, and last, the result, which measures outcomes. A review of 17 studies evaluated e-learning in pharmacy education and classified these studies into the four components of the Kirkpatrick model; it concluded that e-learning directly improved knowledge (Salter et al., 2014). A scoping review of 87 publications reported that $90 \%$ of pharmacy students had a favourable assessment of e-learning while highlighting deficits in social and analytical skills (Lorenzoni et al., 2019). Therefore, this study aims to develop a Moodle-based lesson module for a research course, evaluate its impact on self-reported knowledge and understanding of students, and predict the effect of module contents on outcome variables.

\section{Methods}

This experimental study developed and validated an online Moodle-based research module for pharmacy students. It involved all fourth term Pharm.D. students of the College of Pharmacy, Gulf Medical University, who were required to assess the activity and provide selfreflection reports. The assessment values were subjected to sub-cluster weighting and activity type. The College curriculum and quality assurance committee had approved the design and content of the lesson prior to its implementation.

\section{Content reviewers:}

Two independent reviewers (JAS and SMG) individually assessed the quality of content and validated the learning objectives of the course. Three independent and different faculty members were involved in the assessment process: all student submissions were viewed, and qualitative feedback was provided for debriefing purposes.

\section{Block/Cluster type}

The sequential pattern available on Moodle was used for the activity. Students could not navigate back to previous contents nor proceed to the next activity without submitting their response. Each step was blocked with a mandatory response column. The estimated completion time for the whole lesson was 30-35 working hours. It included content viewing, activity completion, and submission.

\section{Lesson design and conceptual framework}

There were three clusters with a mean expected completion time of nine to eleven hours for each and a specific task and sequential navigation pattern. The students were required to complete all the tasks and activities individually within the allotted duration. Figure 1 illustrates the lesson flow and content distribution.

\section{Moodle-based lesson availability}

The students had access to the lesson for four weeks (28 days), with restriction settings allowing multiple sitting for activity completion. They were encouraged to complete designed activities over several sessions rather than single-attempt. Students were also allowed to repeat the course after completion from the beginning with a maximum of five attempts to evaluate individual learning and improvement of activity submissions. At the end of the lesson, all the students were required to attend the debrief session. The course coordinator provided comprehensive debriefing on the content and activity submissions.

\section{Outcome assessment/parameters}

The following parameters were assessed:

1) The mean and standard deviation (SD) of time (in hours) for module completion, which included both lesson completion and cluster completion.

2) The impact of multi-practice attempts on the completion time and activities assessment score.

3) Self-reported knowledge and understanding, measured on a continuous scale from 0 to 100, before and after taking the cluster (pre and post). These values were then divided into five categories: 0-20 (poor), 21-40 (moderate), 40-60 (good), 60-80 (application level), and 80-100 (expert level). This categorisation was explained to participants in advance, and the same scale was used in every activity for reporting consistency. 


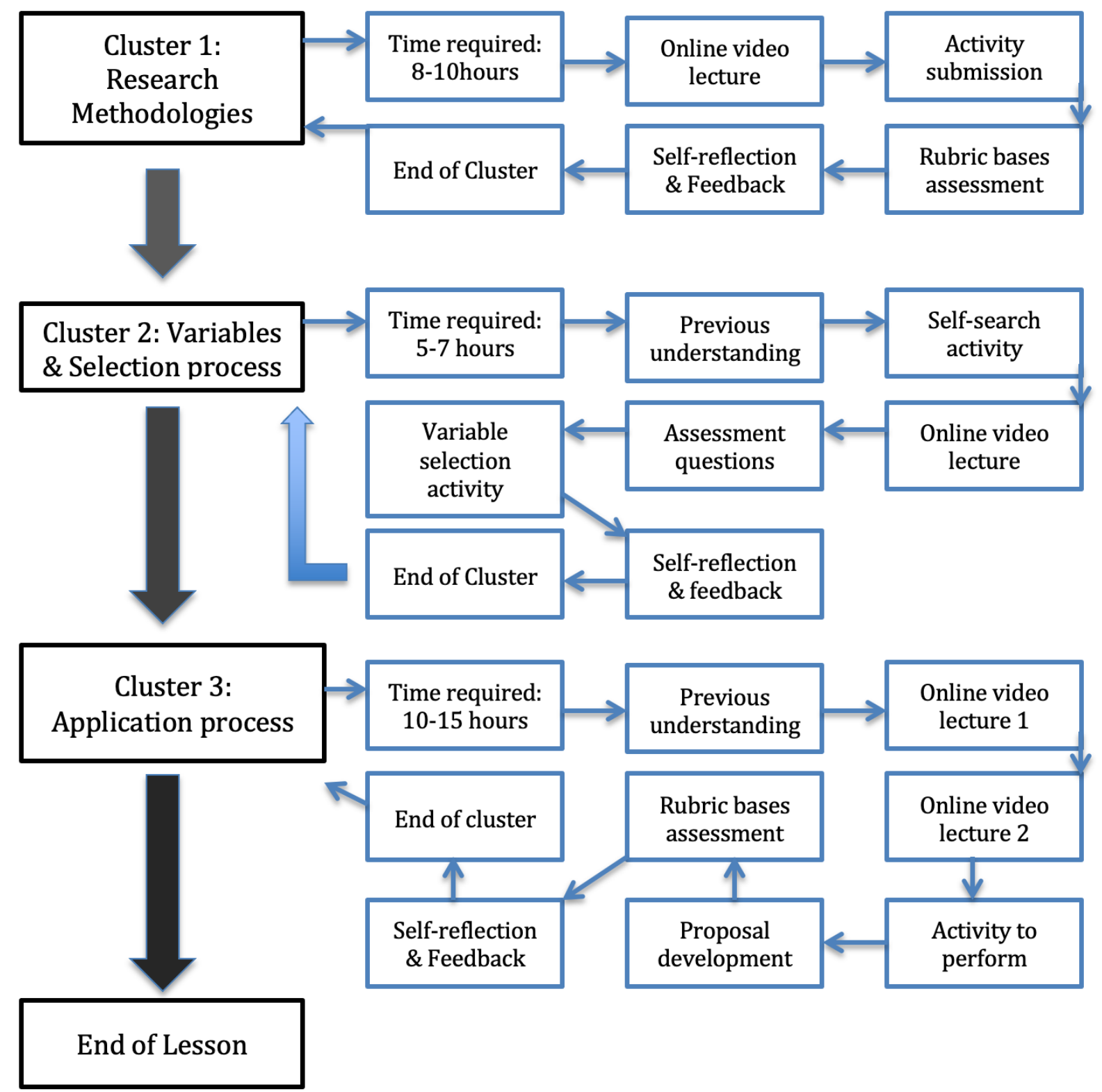

Figure 1: Moodle-based lesson design and content distribution pattern

A faculty member reviewed and assessed feedback of individual clusters qualitatively and reported suggestions to be included in the debriefing list to the principal investigator (SWG) for approval. The principal investigator reviewed all the assessments and submissions for quality assurance and validation purposes.

\section{Statistical analysis:}

Statistical Package for Social Sciences (SPSS) version 21, was used for data analysis. Descriptive and inferential statistical methods were used to evaluate the parameters. The data are presented in both tabulated and graphical forms. Logistic regression modelling was performed to assess the effect of independent variables on primary outcomes. The standard margin of error (5\%) with the confidence of interval (95\%) were used in some significance tests.

\section{Results}

A total of 35 students participated in the Moodle-based research course module. The mean earned score for the module was $81.0 \%$, with an average completion time of 28.5 hours (range 26.8-30.1). A significant difference in completion time was found among gender, higher in males. The performance was significantly associated with hours of lesson completion and earned score (out of a total score of 300). 
Participants who finished the first completion early ( $<10$ days) managed to have practice attempts. Other participants with a delayed first completion ( $>11$ days) showed either two or no practice attempts. Table I presents the details of completion time and scoring patterns.

Table I: Mean completion time and earned score $(\mathrm{N}=35)$

\begin{tabular}{|c|c|c|c|c|c|}
\hline \multirow{2}{*}{$\begin{array}{l}\text { Hours } \\
\text { Mean } \pm \text { SD }\end{array}$} & \multicolumn{3}{|c|}{ Attempts } & \multirow[t]{2}{*}{$p$-value* } & \multirow[t]{2}{*}{ Earned score } \\
\hline & 1 & $2-3$ & $4-5$ & & \\
\hline Lesson \# & $30.1 \pm 2.4$ & $27.4 \pm 3.1$ & $26.8 \pm 2.6$ & 0.001 & $243.4 \pm 8.61$ \\
\hline Cluster $1^{\wedge}$ & $10.3 \pm 3.2$ & $10.1 \pm 2.5$ & $9.8 \pm 2.2$ & 0.754 & $81.6 \pm 6.32$ \\
\hline Cluster $2^{\wedge}$ & $8.5 \pm 2.9$ & $8.1 \pm 3.1$ & $8.2 \pm 2.8$ & 0.671 & $78.2 \pm 5.86$ \\
\hline Cluster $3^{\wedge}$ & $14.2 \pm 3.5$ & $13.8 \pm 3.2$ & $12.2 \pm 3.6$ & 0.022 & $85.1 \pm 6.13$ \\
\hline \multicolumn{6}{|l|}{ Gender $\neq$} \\
\hline Male & $30.7 \pm 2.5$ & $30.2 \pm 2.1$ & $30.4 \pm 2.2$ & 0.001 & $73.6 \pm 4.16$ \\
\hline Female & $29.8 \pm 2.7$ & $29.1 \pm 2.3$ & $28.7 \pm 2.4$ & & $84.7 \pm 9.14$ \\
\hline \multicolumn{6}{|l|}{ Performance } \\
\hline $0-10$ days & $30.4 \pm 1.8$ & $30.1 \pm 2.1$ & $29.8 \pm 2.4$ & 0.003 & $237.5 \pm 9.11$ \\
\hline $11-20$ days & $31.1 \pm 2.3$ & $30.6 \pm 1.9$ & - & & $249.3 \pm 8.32$ \\
\hline $21-28$ days & $33.7 \pm 2.6$ & - & - & & $248.7 \pm 8.67$ \\
\hline
\end{tabular}

*ONE-WAY ANOVA, $\neq$ Student t-Test (significant: $p<0.05$ ), \# total score for the lesson was $300, \wedge$ each cluster earned marks-100

The mean percentages of self-reported knowledge and understanding were significantly increased in all three clusters $(p<0.001)$. There was a significant difference among genders in clusters 2 and 3 . The trends showed a significant increase in self-reported knowledge and understanding of participants in each cluster, except for the knowledge domain in cluster 1.
The intragroup pool analysis also revealed significant differences in gender and performance $(p<0.001)$. In the performance group, the findings suggested a strong positive association with post-module improvement in self-reported understanding in clusters 2 and 3 . The detailed analysis of the self-reported reflection of knowledge and understanding for all clusters is presented in Table II.

Table II: Self-reported reflection of knowledge and understanding (Mean \pm SD) ( $N=35$ )

\begin{tabular}{|c|c|c|c|c|c|c|c|}
\hline \multirow[t]{2}{*}{ Characteristics } & \multirow{2}{*}{$\begin{array}{c}\text { Cluster } 1 \\
\text { KDE }\end{array}$} & & \multirow{2}{*}{$\begin{array}{c}\text { Cluster } 2 \\
\text { KDE }\end{array}$} & \multicolumn{3}{|c|}{ Cluster 3} & \multirow[t]{2}{*}{$p^{*}$} \\
\hline & & UDG & & UDG & KDE & UDG & \\
\hline Pre & $18.1 \pm 3.5$ & $20.1 \pm 4.7$ & $21.6 \pm 4.3$ & $20.4 \pm 3.7$ & $23.3 \pm 3.3$ & $22.4 \pm 4.6$ & 0.001 \\
\hline Post & $69.4 \pm 2.6$ & $75.2 \pm 3.2$ & $70.2 \pm 3.8$ & $79.8 \pm 2.4$ & $77.6 \pm 3.1$ & $80.4 \pm 3.5$ & \\
\hline Pre-post significant & IG & IG & IG & IG & IG & IG & Pool \\
\hline Gender $\neq$ & & & & & & & 0.001 \\
\hline $\begin{array}{l}\text { Male } \\
\text { Female }\end{array}$ & 0.431 & 0.001 & 0.021 & 0.001 & 0.001 & 0.001 & \\
\hline Performance* & & & & & & & 0.001 \\
\hline 0-10 days & - & - & - & - & - & - & \\
\hline $11-20$ days & 0.061 & 0.032 & 0.022 & 0.001 & 0.048 & 0.001 & \\
\hline 21-28 days & 0.054 & 0.041 & 0.016 & 0.001 & 0.013 & 0.001 & \\
\hline
\end{tabular}

Overall, the feedback of participants was satisfactory and limited to contents. It was related to scientific understanding in clusters 2 and 3 . The overall general comments were limited to technical difficulties and time requirements. However, a comprehensive list of debriefing contents was prepared and discussed at the end of the Moodle-based lesson. Table III provides details of the feedback and relevant debriefing contents.

A logistic regression analysis was performed to investigate the effect of independent variables on knowledge and understanding (gender and earned score were adjusted for potential confounders). The regression analysis reported a Nagelkerke's score $R^{2}=0.89$. As presented in Table IV, clusters 1 and 3 (S.E $0.12,95 \% \mathrm{Cl} 1.51-0.67, p=0.025$ \& S.E $0.07,95 \% \mathrm{Cl}$ $0.93-0.43, p=0.001$ ) and performance (S.E 0.11, 95\% $\mathrm{Cl} 0.81-0.24, p=0.037$ ) on completion module were independently and significantly associated with improvement of knowledge in the research module. However, understanding showed a significant and independent association with clusters 2 and 3 (S.E 0.18, $95 \% \mathrm{Cl} 1.66-0.61, p=0.031$ \& S.E $0.11,95 \% \mathrm{Cl} 0.88-$ $0.43 p=0.001$ ), attempts (S.E $0.21,95 \% \mathrm{Cl} 0.72-0.30, p$ $=0.001$ ), and performance (S.E 0.09, 95\% Cl 0.64-0.22, $p=0.022$ ). 
Table III: Student feedback and debriefing contents ( $N=35)$

\begin{tabular}{lll}
\hline Characteristics & Feedbacks' & Debriefing contents \\
\hline General & $\bullet$ Technical difficulties & $\bullet$ Technical assistance provided time-to-time \\
Total: $05(14.2 \%)$ & $\bullet$ Time requirements & - Time-allotted task will be considered for future. \\
& $\bullet$ Addition of instructional manual & Each cluster has well-designed task summary at \\
& beginning.
\end{tabular}

Table IV: Logistic regression analysis with knowledge and understanding

\begin{tabular}{|c|c|c|c|c|c|}
\hline Dependent & Independent & B & S.E & $95 \% \mathrm{Cl}$ & $P$ \\
\hline \multirow[t]{3}{*}{ Knowledge } & Cluster 1 & 0.81 & 0.12 & $1.51-0.67$ & 0.025 \\
\hline & Cluster 3 & 0.67 & 0.07 & $0.93-0.43$ & 0.001 \\
\hline & Performance & 0.48 & 0.11 & $0.81-0.24$ & 0.037 \\
\hline \multirow[t]{4}{*}{ Understanding } & Cluster 2 & 0.89 & 0.18 & $1.66-0.61$ & 0.031 \\
\hline & Cluster 3 & 0.59 & 0.11 & $0.88-0.43$ & 0.001 \\
\hline & Attempts & 0.41 & 0.21 & $0.72-0.30$ & 0.001 \\
\hline & Performance & 0.38 & 0.09 & $0.64-0.22$ & 0.022 \\
\hline
\end{tabular}

The model included all 35 participants and was adjusted for score and gender as potential confounders. Nagelkerke's $R^{2}=0.89$

\section{Discussion}

The average grade of Pharm.D. students at King Saud bin Abdulaziz University for Health Sciences in Riyadh differed significantly between male and female students, with females outperforming their counterparts in professional years 1 to 3 (Alkatheri, Albekairy \& Khalidi, 2019). There was no statistical difference between gender at the University of Central Lancashire when year 1 and 2 pharmacy students filled a questionnaire regarding the impact of Patient As Teacher sessions on their knowledge and communication skills (Lunn et al., 2020). Contrary to these findings, male students needed a higher mean time than female students to complete the course in our study.

In an online preregistration course developed by Monash University, most pharmacy graduates reported benefits of the online course components, such as increased peer support, shared learning, and immediate feedback on their performance (Elliott et al., 2009). Moreover, in an online elective course on current topics in pharmacy developed by the Monroe School of Pharmacy at the University of Louisiana, the faculty was pleased with the performance of students, where students scored more than $90 \%$ in most modules (Pate et al., 2017). A study on online lectures in an introductory drug information course revealed that more than $47 \%$ of students reported better learning with online sessions (Freeman, Schrimsher \& Kendrach, 2006).

In a study about a required online course (with a public health focus) for third professional year pharmacy students at the Thomas Jefferson University, Jefferson College of Pharmacy, Philadelphia, Pennsylvania, the authors reported that online delivery provided students with the flexibility to complete assignments at their convenience, with greater participation by all students and improved self-directed learning (King \& Egras, 2015). A study was conducted by the University of Houston, College of Pharmacy, Texas, on a critical care hybrid online elective course for third-year pharmacy students and compared the student performance in online and traditional learning. The authors reported that the overall examination scores of students were significantly better in the hybrid course (87.7\%) compared to traditional ones (82.6\%) (Wanat, Tucker \& Coyle, 2016). Although our students perceived the learning sessions positively, they reported a few technical difficulties and the need for more time to complete the exercises.

In pharmacy education, feedback was found to improve clinical judgment (Grover, Hayes \& Watson 2014). It constitutes a key mechanism for aiding reflection, knowledge consolidation, and learning in pharmacy 
education. In simulation-based educational research, the relevance for feedback or debriefing on student performance is well documented (Tait, Lee \& Rasiah, 2018). When added to an OSCE, debriefing improved students' performance in preparing care plans for patients (Takeda, Smith \& Cone, 2017). Concordia University Wisconsin School of Pharmacy evaluated the implementation of multiple, content-integrated journal club activities into a large, required medical literature evaluation (MLE) two-term course series, using nearpeer student facilitators. Debriefing was included as one of the activities alongside preparation, quiz, and journal club. The authors reported that faculty-led debriefing ensured that key concepts related to course content were reinforced, take-home points from the article were clear, and any questions from students were addressed (Brown \& Kostrzewa, 2018). In another study, patient simulation was used to prepare student pharmacists to manage medical emergencies in an ambulatory setting. A debriefing session following each simulation led to student pharmacists identifying gaps in care and formulating strategies for changing behaviours to improve care in the future (Robinson et al., 2011).

There is strong evidence of a positive relationship between feedback as a teaching mode and the learners' performance (Shute, 2008). Australian researchers conducted a mixed-methods study in which pharmacy student participants completed casebased scenarios within different simulation modalities, with feedback provided to them at the completion of each scenario. The participants reported that feedback allowed knowledge consolidation and facilitated reflective learning with high interactivity (Tait, Lee \& Rasiah, 2018). A role play assessed pharmacy students from Jordan on their ability to conduct a simulated patient medication interview. During the learning activity, each student received immediate feedback (debriefing) based on the marking criteria to ensure that the students received similar and tailored feedback, which led to positive outcomes on student learning (Bajis et al., 2019). A study conducted at Queen's University Belfast investigated students' views on faculty feedback and their satisfaction with the faculty feedback on their academic performance. In this study, only $32.3 \%$ were satisfied with the feedback received, and most of them were dissatisfied with the examination feedback (Hall, Hanna \& Quinn, 2012). In our study, the feedback of participants was satisfactory overall, with some participants reporting technical difficulties and time requirement issues. However, a comprehensive list of debriefing contents was prepared and discussed at the end of the Moodlebased lesson.
Online learning contributes positively to the knowledge of pharmacists (Nesterowicz, Librowski \& Edelbring, 2014). A study investigating knowledge about antibiotics and antimicrobial resistance among pharmacy students in Sri Lanka reported that senior pharmacy students had a significantly higher knowledge than junior pharmacy students (Sakeena, Bennett \& Jamshed, 2018). In another study from Malaysia, the authors reported that senior pharmacy students have a higher knowledge of cardiology, pharmacy education, and training, attributed to the greater exposure of senior students to the real-world scenario in hospital settings (Elnaem et al., 2018).

Various factors affect the exam completion time, including personality, prior knowledge, metacognitive accuracy, and current knowledge. Exam completion time was negatively associated with the scores, i.e. students who completed the exam faster had better scores. In this study, the variable associated with student performances was the number of hours needed to complete the lesson. Oppositely to the above studies, only second-year pharmacy students attended this course. The results of this study can be considered contradictory with previous findings, as students who completed the activity faster scored higher. Further investigations are required to evaluate the impact of learning style on scoring patterns.

Offering pharmacy students a chance to experience research, data analysis, and discussing research projects is essential to provide them with the necessary confidence to conduct research (Ramsauer, 2011). Anxiety among students should be considered in online teaching where there is less direct contact with the faculty, and students must perform activities independently. The instructors' involvement and connection with students are essential during online activities (Rapp-McCall \& Anyikwa, 2016). It has been suggested that student participation in online research sessions was less intimidating, thus enhancing the quality and quantity of interaction during online classes (Ni, 2013). A study comparing online and face-to-face discussions in a web-based research course reported that performance was significantly correlated with the number of messages read and posted in the online group (Campbell et al., 2008). A study at the University of South Carolina suggested including enhanced training in research methods, biostatistics, and literature evaluation in Pharm.D. programs and residency training sites, as understanding biostatistics and research study design showed to be poor among pharmacy residents. Those who received previous training had better scores than those who did not, with significant mean differences in knowledge scores by attitude and confidence (Bookstaver et al., 2012). 
A study among all students enrolled in each year of the four-year pharmacy undergraduate program at the University of Sydney, Australia, reported that positive attitudes and perspectives towards research were strongly influenced by exposure to the research process through projects, friends or mentors, previous degrees, or having future intentions to pursue a research degree (Kritikos et al., 2015). Fostering a research culture among students increases their engagement in research (Harirforoosh \& Stewart, 2016). In our study, performance in module completion was independently and significantly associated with improvement in knowledge in the research module.

\section{Conclusion}

This study showed that the online Moodle-based lesson module for a research course is an effective and validated tool to improve the knowledge and understanding of pharmacy students. It also revealed constructive feedback for debriefing sessions. Further behavioural analysis will help determine the independent characteristics of attempts and performance attitude.

\section{Ethical and consent to participate}

Gulf Medical University Ethical Committee ruled that no formal ethical approval was required in this particular case. The College of Pharmacy Assessment and Curriculum Development committee has been informed and consented before the design of the MOODLE-based lesson. Written informed consent was taken from all the participants.

\section{Consent for publication}

Written consent was taken from all the participants for the publication. The anonymity and privacy were thoroughly reviewed during analysis and draft writing.

\section{Availability of data and materials}

All data generated or analysed during this study are included in this published article.

\section{Competing interests}

The authors declare that they have no competing interests.

\section{Authors' contributions}

SWG: principal investigator, content design and interpretation.

SMG: internal validation, data collection \& analysis

JAS: data analysis and draft writing

RAA: data collection and draft writing

All the authors have read and approved the manuscript.

\section{Acknowledgment:}

The authors would like to express their gratitude to pharmacy students' at Gulf Medical University, Ajman, United Arab Emirates (UAE).

\section{References}

Alkatheri, A.M., Albekairy, A.M., Khalidi, N (2019). Implementation of an ACPE-Accredited PharmD Curriculum at a Saudi College of Pharmacy. Am J Pharm Educ. 83(9):6237. https://doi.org/10.5688/ajpe6237

Bajis, D., Chaar, B., Basheti, I.A., Moles, R. (2019) Pharmacy students' medication history taking competency: Simulation and feedback learning intervention. Curr Pharm Teach Learn. 11(10):1002-1015.

https://doi.org/10.1016/j.cptl.2019.06.007

Bookstaver, P.B., Miller, A.D., Felder, T.M., Tice, D.L., Norris, L.B., Sutton, S.S. (2012) Assessing pharmacy residents' knowledge of biostatistics and research study design. Ann Pharmacother. 46(7-8):991-999.

https://doi.org/10.1345/aph.1Q772

Brown, M.C., Kostrzewa, A.B. (2018) Implementation and Evaluation of Near-Peer Facilitated Journal Club Activities in a Required MLE Course Series. Am J Pharm Educ. 82(8):6718. doi:10.5688/ajpe6718. https://doi.org/10.5688/ajpe6718

Campbell, M., Gibson, W., Hall, A., Richards, D., Callery, P. (2008) Online vs. face-to-face discussion in a web-based research methods course for postgraduate nursing students: A quasi-experimental study. International Journal of Nursing Studies. 45(5):750-9.

https://doi.org/10.1016/j.ijnurstu.2006.12.011

Cook, D.A., Levinson, A.J., Garside, S., Dupras, D.M., Erwin, P.J., Montori, V.M., (2010). Instructional design variations in Internet-based learning for health professions education: a systematic review and meta-analysis. Acad Med. 85(5):909922. https://doi.org/10.1097/ACM.0b013e3181d6c319 
Cook, D.A., Levinson, A.J., Garside, S., Dupras, D.M., Erwin, P.J., Montori, V.M. (2008). Internet-based learning in the health professions: a meta-

analysis. JAMA. 300(10):1181. https://doi.org/10.1001/jama .300 .10 .1181

COVID-19 Educational Disruption and Response [Internet]. UNESCO. 2020 [cited 22 May 2020]. Available from: https://en.unesco.org/covid19/educationresponse

Distance learning system to continue to be applied till end of current academic year [internet]. United Arab Emirates Ministry of Education. 2020 [cited 22 May 2020]. Available from:

https://www.moe.gov.ae/En/MediaCenter/News/Pages/ele arning3.aspx

Elliott, R.A., McDowell, J., Marriott, J.L., Calandra, A., Duncan, $G$ (2009). A pharmacy preregistration course using online teaching and learning methods. Am J Pharm Educ. 73(5):77. https://doi.org/10.5688/aj730577

Elnaem, M.H., Bin, Che, Ibrahim, M.Z., Abdul, Rahman, N.A.H., Binti, Mahyidin, N.H., Binti, Sulaiman, N.M., Binti, Zulkiflee, F.A. (2018) Knowledge and perceptions toward cardiology pharmacy education and training: Malaysian pharmacy students' perspectives. Curr Pharm Teach Learn. 10(4):453-462. https://doi.org/10.1016/j.cptl.2017.12.019

Freeman, M.K., Schrimsher, R.H., Kendrach, M.G. (2006) Student perceptions of online lectures and WebCT in an introductory drug information course. Am J Pharm Educ. 70(6):126. https://doi.org/10.5688/aj7006126

Grover, B., Hayes, B.D., Watson, K. (2014) Feedback in clinical pharmacy education. Am J Health Syst Pharm. 71(18):1592-1596. https://doi.org/10.2146/ajhp130701

Hall, M., Hanna, L.A., Quinn, S. (2012) Pharmacy students' views of faculty feedback on academic performance. Am J Pharm Educ. 76(1):5. https://doi.org/10.5688/ajpe7615

Harirforoosh, S., Stewart, D.W. (2016) A descriptive investigation of the impact of student research projects arising from elective research courses. BMC Res Notes. 9:48. https://doi.org/10.1186/s13104-016-1865-1

King, A.E., Egras, A.M. (2015) A Required Online Course with a Public Health Focus for Third Professional Year Pharmacy Students. Am J Pharm Educ. 79(5):68. https://doi.org/10.5688/ajpe79568

Ko, S., Rossen, S., (2017) Teaching Online: A Practical Guide.4th ed. New York, NY, USA:Routledge. https://doi.org/10.4324/9780203427354

Kritikos, V.S., Saini, B., Carter, S., Moles, R.J., Krass, I. (2015) Factors influencing pharmacy students' attitudes towards pharmacy practice research and strategies for promoting research interest in pharmacy practice. Pharm Pract (Granada). 13(3):587.

https://doi.org/10.18549/PharmPract.2015.03.587

Lorenzoni, A.A., Manzini, F., Soares, L., Leite, S.N (2019). Elearning in Pharmacy Education: what do we know about it?. Braz. J. Pharm. Sci. 55, e18100. https://doi.org/10.1590/s2175-97902019000118100
Lunn, A.M., Urmston, A., Seymour, S., Manfrin, A (2020). Patient as teacher sessions contextualize learning, enhancing knowledge, communication, and participation of pharmacy students in the United Kingdom. J Educ Eval Health Prof. 17:15. https://doi.org/10.3352/jeehp.2020.17.15

Muro, M., Maxim, R., Whiton, J. (2020). The places a COVID19 recession will likely hit hardest [internet]. Brookings. [cited 22 May 2020]. Available from: https://www.brookings.edu/blog/theavenue/2020/03/17/the-places-a-covid-19-recession-willlikely-hit-hardest/amp/

Nesterowicz, K., Librowski, T., Edelbring, S. (2014) Validating e-learning in continuing pharmacy education: user acceptance and knowledge change. BMC Med Educ. 14:33. https://doi.org/10.1186/1472-6920-14-33

Ni, A.Y. (2013) Comparing the effectiveness of classroom and online learning: Teaching research methods. Journal of Public Affairs Education. 19(2):199-215.

https://doi.org/10.1080/15236803.2013.12001730

Pate, K.A., Pate, A.N., Sampognaro, L.A., Brady, J.H., Caldwell, D.J (2017). Design, implementation, and evaluation of an online elective course on current topics in pharmacy. Curr Pharm Teach Learn. 9(4):528-536. https://doi.org/10.1016/j.cptl.2017.03.008

Ramsauer, V.P. (2011) An elective course to engage pharmacy students in research activities. Am J Pharm Educ. 75(7):138. https://doi.org/10.5688/ajpe757138

Rapp-McCall, L.A., Anyikwa, V. (2016) Active learning strategies and instructor presence in an online research methods course: Can we decrease anxiety and enhance knowledge?. Advances in Social Work. 25; 17(1):1-4. https://doi.org/10.18060/20871

Robinson, J.D., Bray, B.S., Willson, M.N., Weeks, D.L. (2011) Using human patient simulation to prepare student pharmacists to manage medical emergencies in an ambulatory setting. Am J Pharm Educ. 75(1):3. https://doi.org/10.5688/ajpe7513

Sakeena, M.H.F., Bennett, A.A., Jamshed, S., (2018). Investigating knowledge regarding antibiotics and antimicrobial resistance among pharmacy students in Sri Lankan universities. BMC Infect Dis. 18(1):209. https://doi.org/10.1186/s12879-018-3107-8

Salter, S.M., Karia, A., Sanfilippo, F.M., Clifford, R.M (2014). Effectiveness of E-learning in pharmacy education. Am J Pharm Educ. 78(4):83. https://doi.org/10.5688/ajpe78483

Shute, V.J. (2008) Focus on formative feedback. Review of educational research. 78(1):153-89.

https://doi.org/10.3102/0034654307313795

Statement on the second meeting of the International Health Regulations (2005) Emergency Committee regarding the outbreak of novel coronavirus (2019-nCoV) [internet]. World Health Organization. 2020 [cited 22 May 2020]. Available from: https://www.who.int/news-room/detail/3001-2020-statement-on-the-second-meeting-of-theinternational-health-regulations-(2005)-emergencycommittee-regarding-the-outbreak-of-novel-coronavirus(2019-ncov) 
Sun, A., Chen, X., (2016) Online education and its effective practice: A research review. JITE: Research. 15: 157-190. https://doi.org/10.28945/3502

Tait, L., Lee, K., Rasiah, R. (2018). Simulation and Feedback in Health Education: A Mixed Methods Study Comparing Three Simulation Modalities. Pharmacy (Basel). 6(2):41. https://doi.org/10.3390/pharmacy6020041

Takeda, M.Y., Smith, M.J., Cone, C.J. (2017) Debriefing to Improve Student Ability to Assess and Plan for the Care of Persons With Disability. Simul Healthc. 12(6):356-363. https://doi.org/10.1097/SIH.0000000000000272

Wanat, M.A., Tucker, A.M., Coyle, E.A. (2016) A Critical Care Hybrid Online Elective Course for Third-Year Pharmacy Students. Am J Pharm Educ. 80(9):154.

https://doi.org/10.5688/ajpe809154

WHO Director-General's opening remarks at the media briefing on COVID-19 - 11 March 2020 [internet]. World Health Organization. 2020 [cited 22 May 2020]. Available from: https://www.who.int/dg/speeches/detail/whodirector-general-s-opening-remarks-at-the-media-briefingon-covid-19---11-march-2020

Wong, G., Greenhalgh, T., Pawson, R., (2010) Internet-based medical education: a realist review of what works, for whom and in what circumstances. BMC Med Educ. 10:12.

https://doi.org/10.1186/1472-6920-10-12

Yardley, S.T., (2012) Kirkpatrick's levels and education 'evidence.' Med Educ. 46(1):97-106.

https://doi.org/10.1111/j.1365-2923.2011.04076.x 